Revista Brasileira de Agricultura Irrigada v.12, nº.4, p. 2776 - 2783, 2018

ISSN 1982-7679 (On-line)

Fortaleza, CE, INOVAGRI - http://www.inovagri.org.br

DOI: $10.7127 /$ rbai.v12n400975

Protocolo 975.18 - 22/06/2018 Aprovado em 03/07/2018

\title{
IMPACTO DO USO DE EFLUENTES NAS CARACTERÍSTICAS DO SOLO CULTIVADO COM QUIABO (Abelmoschus esculentus L)
}

\author{
Camila Kaliane dos Santos ${ }^{1}$, Fabiano Santos Santana ${ }^{2}$, Francyelle Souza de Menezes Ramos ${ }^{3}$, \\ Gregorio Guirada Faccioli ${ }^{4}$, Raimundo Rodrigues Gomes Filho ${ }^{5}$
}

\section{RESUMO}

Com fins de economizar o uso da água no mundo vem sendo praticado o reuso de águas residuárias na irrigação, a reutilização do recurso natural, água, está cada vez mais tomando espaço no meio científico. Assim, este trabalho teve como objetivo analisar o potencial do impacto do uso dos efluentes nas características do solo cultivado com quiabo (Abelmoschus esculentus L). A pesquisa foi desenvolvida em ambiente protegido, localizado na Universidade Federal de Sergipe - UFS. Foram utilizadas duas fontes de água, sendo água potável da Companhia de Saneamento de Sergipe (DESO), coletada diariamente em uma torneira, situada dentro do ambiente protegido e efluente tratado doméstico, proveniente da Estação de Tratamento de Esgoto ETE da UFS, localizada no município de São Cristóvão - SE. O delineamento experimental foi em Blocos Casualizados (DBC) composto por três tratamentos (100\% da água de abastecimento da DESO; $100 \%$ efluente; e 50\% água da DESO + 50\% efluente), oito repetições, totalizando 24 vasos. O tratamento com 100\% de efluente doméstico tratado favoreceu o aumento de matéria orgânica e teores de sódio no solo.

Palavras-chave: águas residuárias, sódio, matéria orgânica.

\section{IMPACT OF THE USE OF EFFLUENTS ON SOIL CHARACTERISTICS CULTIVATED WITH OKRA (Abelmoschus esculentus L)}

\footnotetext{
ABSTRACT

In order to save water use in the world, wastewater reuse has been practiced in irrigation, the reuse of the natural resource, water, is increasingly taking place in the scientific environment. Thus, this work aimed to analyze the potential of the impact of the use of effluents on the characteristics of the soil cultivated with okra (Abelmoschus esculentus $L$ ). The research was

${ }^{1}$ Graduanda em Engenharia Agrícola, DEAGRI/UFS. São Cristovão-SE. E-mail: camilakaliane@hotmail.com;

2 Graduando em Engenharia Agrícola, DEAGRI/UFS. São Cristovão-SE. E-mail: engagrifabianoufs@hotmail.com;

${ }^{3}$ Engenheira Agrícola, DEAGRI/UFS. São Cristovão-SE. E-mail: francyelle_ramos10@hotmail.com;

${ }^{4}$ Doutor em Engenharia Agrícola, professor da UFS, São Cristovão, Sergipe. gregorioufs@gmail.com;

${ }^{5}$ Doutor em Engenharia Agrícola, professor da UFS, São Cristóvão, Sergipe. rrgomesfilho@hotmail.com.
} 
developed in a protected environment, located at the Federal University of Sergipe - UFS. Two sources of water were used, being drinking water from the Sergipe Sanitation Company (DESO), collected daily in a faucet, located inside the protected environment and domestic treated effluent, from the Sewage Treatment Station of the Federal University of Sergipe. The present study was developed in a randomized block design (DBC), composed of three treatments (100\% of the supply water of the DESO, 100\% effluent, and 50\% water of the DESO + 50\% effluent), eight replications, totalizing 24 vessels. The treatment with $100 \%$ treated domestic effluent favored the increase of organic matter and sodium contents in the soil.

Keywords: wastewater, sodium, organic matter.

\section{INTRODUÇÃO}

A aplicação de efluentes no solo é uma forma de grande eficácia no controle da poluição e uma alternativa viável para o aumento da disponibilidade hídrica, principalmente em regiões áridas e semiáridas, permitindo maiores benefícios nos aspectos econômicos, ambientais e de saúde pública (PAGANINI, 2003).

As águas residuárias vêm sendo utilizadas cada vez mais para a irrigação de diversas espécies vegetais. Na Universidade Federal de Sergipe já existem pesquisas referentes ao tema, como Carvalho et al. (2013) para girassol; Dantas et al. (2014) para rabanete; e Doria et al. (2015) para cenoura e beterraba.

Segundo Hespanhol (2003), o reuso planejado de águas é uma alternativa potencial de racionalização desse bem natural.
Existem diversos tipos de reuso, os mais utilizados são o urbano, o industrial e o agrícola. O reuso agrícola se caracteriza como aquele que ocorre quando o efluente de ETES (Estações de Tratamento de Esgotos) é utilizado para a irrigação no cultivo de espécies agrícolas.

Nesse contexto, objetivo desse trabalho foi analisar o potencial do impacto do uso de efluente doméstico tratado nas características do solo cultivado com quiabo.

\section{MATERIAL E MÉTODOS}
O experimento foi conduzido em ambiente protegido, localizada no Departamento de Engenharia Agronômica da Universidade Federal de Sergipe, no município de São Cristóvão, Sergipe (Figura 1).

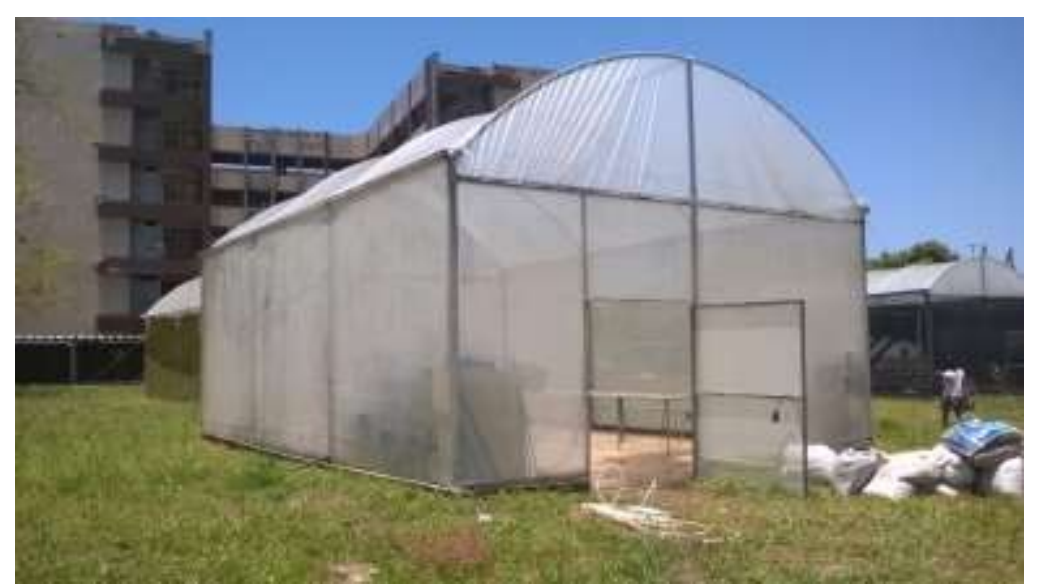

Figura 1. Vista lateral da casa de vegetação utilizada no experimento (DEA/UFS).

Fonte: Registro fotográfico obtido durante o experimento, 2017.

Como forma de evitar interferências na passagem da luz solar e que manchas pudessem bloquear a captação da radiação foi feita uma limpeza da parte lateral do ambiente protegido. (Figura 2). 


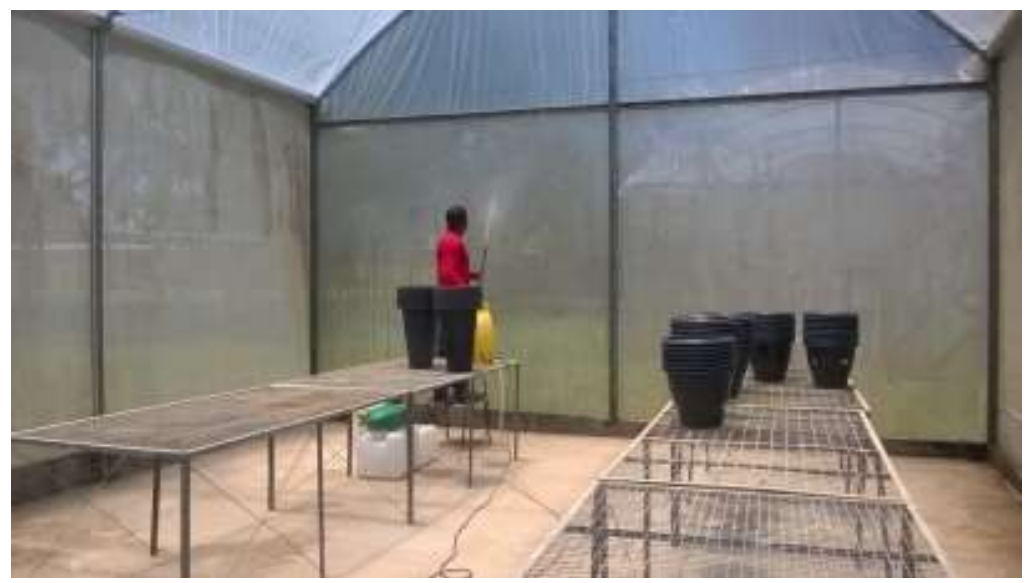

Figura 2. Limpeza da parte lateral. Fonte: Registro fotográfico obtido durante o experimento, 2017.

O solo utilizado nesse experimento foi reaproveitado do experimento anterior cultivado com a cultura do pimentão.

As sementes que foram utilizadas no experimento são da empresa ISLA Sementes, Quiabo SANTA CRUZ 47.

A pesquisa foi concebida em blocos casualizados (DBC), submetida a três concentrações de efluente doméstico tratado $\mathrm{T}_{1}$ (100\% de água de abastecimento da DESO), $\mathrm{T}_{2}$ (50\% de efluente doméstico tratado $+50 \%$ de água de abastecimento da DESO) e $\mathrm{T}_{3}$ (100\% de efluente doméstico tratado) e oito repetições, totalizando 24 vasos.

Dentro do ambiente protegido foi instalado uma estação meteorológica automática, para coleta de dados climáticos (temperaturas, umidade relativa, radiação solar e velocidade do vento) que foram utilizados diariamente para a estimativa da demanda hídrica da cultura. (Figura $3)$.

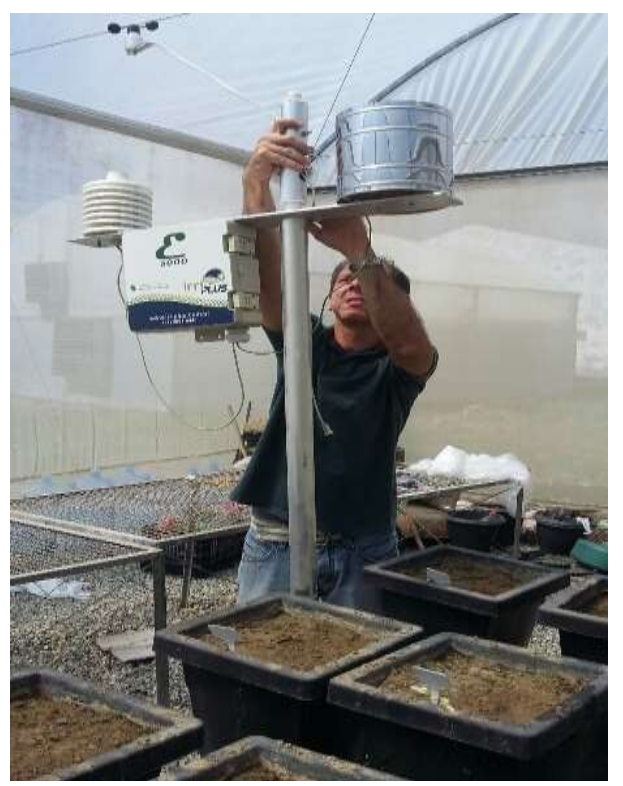

Figura 3. Estação Meteorológica Automática. Fonte: Registro fotográfico obtido durante o experimento, 2017.

No dia 6 de março de 2017 foram realizados, simultaneamente, o plantio e a adubação de plantio. Como procedimento foram plantadas 3 sementes/vaso em fileira no meio do vaso. Após a semeadura, foi realizada a irrigação de saturação, até a germinação de todas as sementes, composta por $400 \mathrm{ml}$ de água potável DESO duas vezes por dia, buscando a possibilidade de germinações uniformes e um bom desenvolvimento. Na adubação de plantio todos os tratamentos receberam 
superfosfato triplo no valor de 8,8 g/vaso.

(Figura 4)

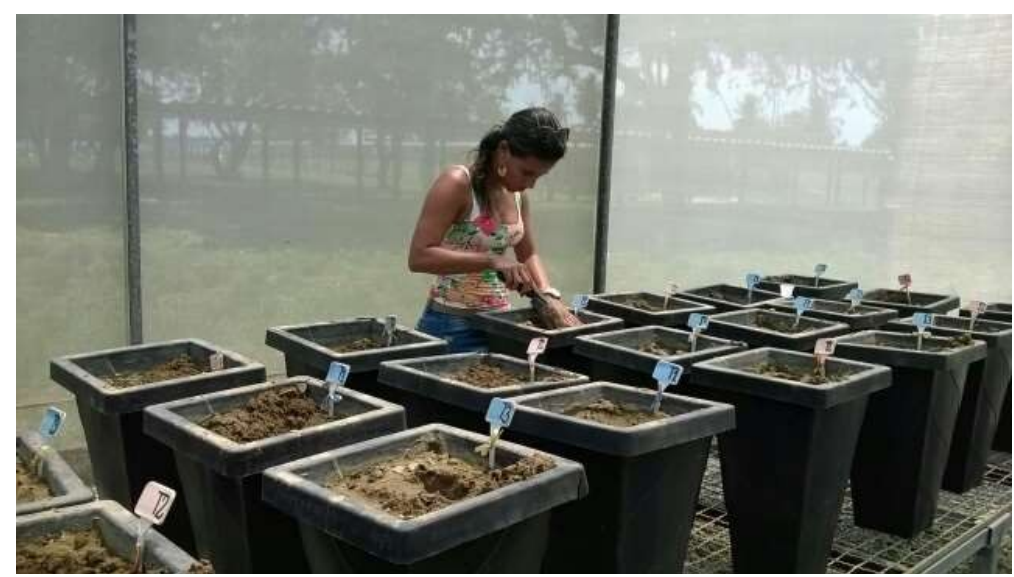

Figura 4. Semeadura. Fonte: Registro fotográfico obtido durante o experimento, 2017.

Quando a germinação em todos os vasos ocorreu de forma satisfatória foi feito o desbaste com 30 dias após a semeadura, deixando apenas uma planta por vaso. As adubações de cobertura foram realizadas nos dias 30 de março e 3 de maio de 2017, apenas para os tratamentos T1. A adubação de cobertura foi aplicada parceladamente, utilizando-se 3,61 gramas de uréia por vaso e 2,48 gramas de Cloreto de potássio por vaso. A partir do dia 30 de março iniciou se a irrigação com água deso e efluente.

Este experimento contou com duas fontes distintas de água: água potável da DESO, coletada diariamente em uma torneira, situada dentro da casa de vegetação e água residuária tratada, proveniente da ETE UFS, localizada no município de São Cristóvão - SE, coletada e transportada duas vezes na semana até o local do reservatório plástico de 20 litros (Figura 5). 


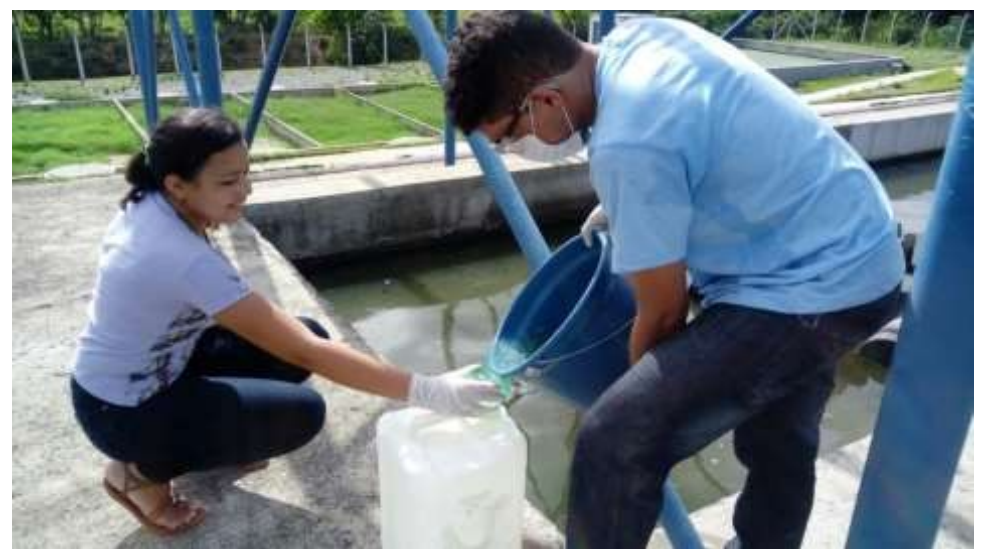

Figura 5. Coleta de efluente. Fonte: Registro fotográfico obtido durante o experimento, 2017.

A ETE utilizada no estudo é alimentada pelo esgoto sanitário em dois pontos: um no tanque facultativo primário, que representa a maior contribuição do sistema, segundo informações do técnico da UFS, recebendo o esgoto proveniente da estação elevatória; outro no tanque facultativa secundária, que recebe 0 esgoto por gravidade. Em ambos pontos, o esgoto chega na unidade de prétratamento, composto por grade e caixa de areia, sendo então encaminhado ao tanque final (Figura 6).

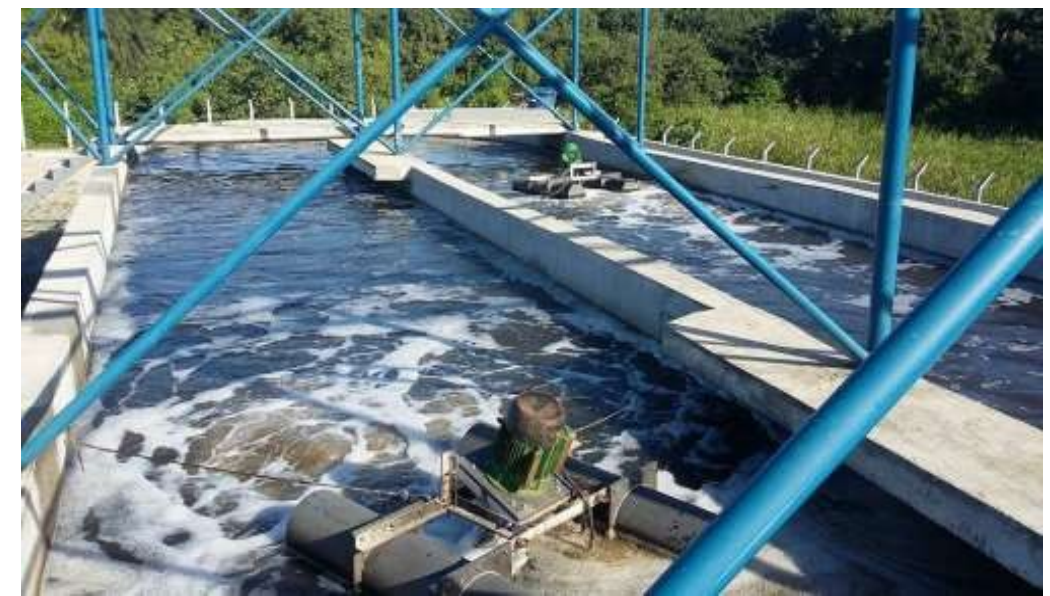

Figura 6. Tanque de Coleta. Fonte: Registro fotográfico obtido durante o experimento, 2017. 
A aplicação de água nos vasos foi realizada manualmente por meio de proveta graduada de $100 \mathrm{~mL}$, semelhante a uma irrigação localizada. A diferenciação dos tratamentos começou no dia 30 de março de 2017.

A colheita foi realizada no dia 1 de junho de 2017 com 85 dias após a semeadura (Figura 7).

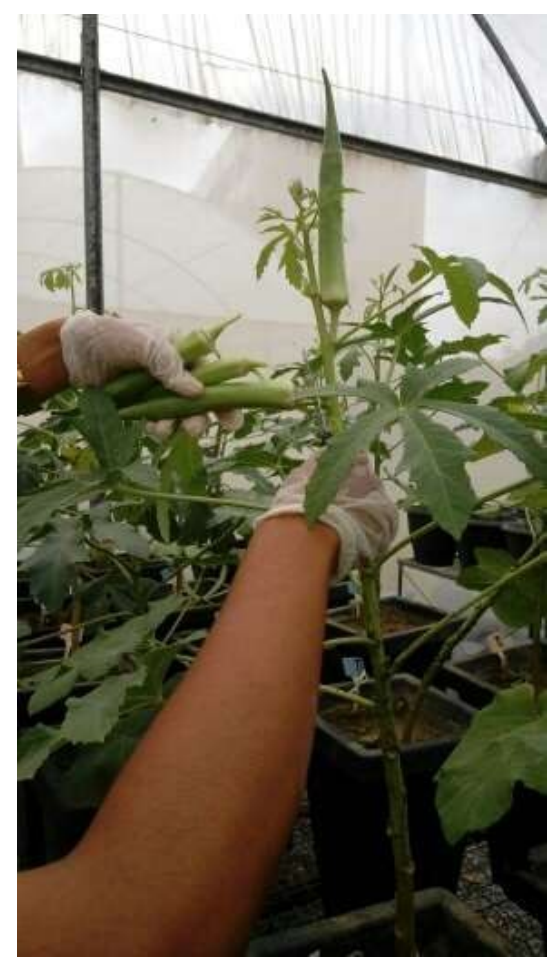

Figura 7. Colheita. Fonte: Registro fotográfico obtido durante o experimento, 2017.

O solo foi coletado em dois momentos, no inicio e no final do experimento. Para formar a amostra foi coletado uma camada fina com profundidade de $20 \mathrm{~cm}$ e espessura de 2 $\mathrm{cm}$, onde as bordas foram descartadas, esse procedimento foi repetido em cada vaso e colocado a um saco plástico, onde todo o solo foi homogeneizado e retirado uma amostra de 1000g para ser levado ao laboratório.

\section{RESULTADOS E DISCUSSÃO}

Na Tabela 1 podem ser observados os resultados das análises químicas do solo realizadas antes da aplicação do efluente doméstico tratado e após a colheita da cultura.

Tabela 1. Análise química do solo antes da aplicação do efluente e após a colheita da cultura

\begin{tabular}{lcccccc}
\hline \multirow{2}{*}{ ENSAIOS } & \multicolumn{3}{c}{ Antes da aplicação do efluente } & \multicolumn{3}{c}{ Após a colheita da cultura } \\
\cline { 2 - 7 } & $\mathrm{T} 1$ & $\mathrm{~T} 2$ & $\mathrm{~T} 3$ & $\mathrm{~T} 1$ & $\mathrm{~T} 2$ & $\mathrm{~T} 3$ \\
\hline Matéria Orgânica $\left(\mathrm{g} \mathrm{dm}^{-3}\right)$ & 9,50 & 9,18 & 8,87 & 12,2 & 12,5 & 14,1 \\
\hline Sódio $\left(\mathrm{cmol} \mathrm{dm}^{-3}\right)$ & 0,115 & 0,193 & 0,131 & 0,083 & 0,197 & 0,203 \\
\hline PST $(\%)$ & 2,48 & 3,95 & 2,68 & 2,48 & 3,99 & 3,75 \\
\hline Magnésio $\left(\mathrm{cmol} \mathrm{dm}^{-3}\right)$ & 0,64 & 2,16 & 1,02 & 0,40 & 0,53 & 0,60 \\
\hline Potássio $\left(\mathrm{cmol} \mathrm{dm}^{-3}\right)$ & 0,03 & 0,02 & 0,07 & 0,13 & 0,04 & 0,04 \\
\hline pH & 6,87 & 6,15 & 6,85 & 7,26 & 6,29 & 6,27 \\
\hline CTC $\left(\mathrm{cmol}_{\mathrm{c}} \mathrm{dm}^{-3}\right)$ & 4,64 & 4,88 & 4,89 & 3,35 & 4,94 & 5,41 \\
\hline
\end{tabular}

De acordo com a Tabela 1, antes da aplicação do efluente doméstico tratado o valor de matéria orgânica foi de $9,50 \mathrm{~g} / \mathrm{dm}^{3}$ e no final do experimento observou-se um pequeno 
aumento no valor para o tratamento $\mathrm{T} 1(12,2$ $\left.\mathrm{g} / \mathrm{dm}^{3}\right)$ e no Tratamento $2\left(12,5 \mathrm{~g} / \mathrm{dm}^{3}\right)$. Entretanto, no T3 percebeu-se um aumento maior, o qual já era esperado, pois o efluente é composto por resíduos orgânicos em decomposição.

A adição de matéria orgânica tem apresentado efeitos muitas vezes contraditórios sobre o $\mathrm{pH}$ do solo. De acordo com Bouwer (2000), em solos que receberam águas residuárias pode haver diminuição no valor de $\mathrm{pH}$ em virtude da degradação dos resíduos biodegradáveis que propicia a produção de $\mathrm{CO}_{2}$ e ácidos orgânicos. Queiroz et al. (2004) notaram redução do pH nas parcelas de solo que receberam água residuária de suinocultura. Por outro lado, tem-se observado incrementos no valor de $\mathrm{pH}$ do solo quando fertirrigados com águas residuárias em sistemas agrícolas de pastagens (QUIN \& WOODS, 1978) e florestas (CROMER et al., 1984). Neste trabalho, verificou um aumento do $\mathrm{pH}$ para os tratamentos T1 e T2, porém uma ligeira redução do $\mathrm{pH}$ para o tratamento com 100\% de efluente doméstico tratado (T3).

Em comparação com os resultados de sódio antes da diferenciação $\left(0,115 \mathrm{cmol} / \mathrm{dm}^{3}\right)$ e do tratamento T1 $\left(0,083 \mathrm{cmol} / \mathrm{dm}^{3}\right)$, o sódio apresentou acréscimo nos tratamentos com efluente, sendo em T2 $\left(0,197 \mathrm{cmol} / \mathrm{dm}^{3}\right)$ em menor quantidade do que em T3 $(0,203$ $\mathrm{cmol} / \mathrm{dm}^{3}$ ) já que sua irrigação com efluente foi de apenas 50\%. Em geral, as concentrações de $\mathrm{Na}^{+}$são elevadas após a aplicação de águas residuárias, principalmente nas camadas superficiais (CROMER et. al, 1984).

Os tratamentos que receberam efluente doméstico tratado tiveram seus valores aumentados no que tangente a CTC, tanto na proporção de $50 \%$ como de $100 \%$ de efluente.

Queiroz et al. (2004), utilizando água residuária de suinocultura obtiveram aumento na soma de bases e na CTC do solo; entretanto, verificaram redução na saturação por bases, possivelmente em razão do aumento da concentração de $\mathrm{Al}^{+3}$ no solo.
Aumentos na CTC e saturação por bases também foram observados com o uso de água residuária da lavagem e despolpa dos frutos do cafeeiro conilon (GARCIA, 2003) e com efluente de esgoto tratado (FONSECA et al., 2005).

Em geral, os aumentos na CTC e na saturação por bases com a aplicação de águas residuárias são atribuídos à alta concentração de íons e aos colóides orgânicos presentes nos efluentes.

\section{CONCLUSÕES}

A aplicação de efluente doméstico tratado no solo para o cultivo do quiabo proporcionou um aumento nos teores de matéria orgânica, sódio e na capacidade de troca de cátions.

\section{REFERÊNCIAS}

BOUWER, H. Groundwater problems caused by irrigation with sewage effluent. Journal of Environmental Health, v.63, p.17-20. 2000.

CARVALHO, R. S. de; SANTOS FILHO, J. S. dos; SANTANA, L. O. G. de; GOMES, D. A.; MENDONÇA, L. C.; FACCIOLI, G. G. Influência do reuso de águas residuárias na qualidade microbiológica do girassol destinado à alimentação animal. Revista Ambiente \& Água, v. 8, n. 2, p. 157-167. 2013.

CROMER, R. N.; TOMPKINS, D.; BARR, N. J.; HOPMANS, P. Irrigation of monterey pines with wastewater: Effect on soil chemistry and groundwater composition. Journal of Environmental Quality, v.13, p.539-542, 1984.

DANTAS, I. L. de A.; FACCIOLI, G. G.; MENDONÇA, L. C.; NUNES, T. P.; VIEGAS, P. R. A.; SANTANA, L. O. G de. Viabilidade do uso de água residuárias tratada na irrigação da cultura do rabanete (Raphanus sativa L.). Revista Ambiente \& Água, v. 9, n. 1, jan./mar. 2014. 
DORIA, B. R. S.; TAVARES, L. O. G. de S.; RAMOS, F. S. de M.; SOUZA, J. A.; SANTOS, D. M.; FACCIOLI, G. G. Determinação da demanda hídrica das culturas cenoura e beterraba, irrigadas com água residuárias em condições de casa de vegetação em São Cristóvão-SE In: XXV CONIRD Congresso Nacional de Irrigação e Drenagem. São Cristóvão-SE. Anais. 2015.

FONSECA, A. F.; MELFI, A. J.; MONTES, C. R. Maize growth and changes in soil fertility after irrigation with treated sewage effluent. II. Soil acidity, exchangeable cations, and sulfur, boron and heavy metals availability. Communications in Soil Science and Plant Analysis, v.36, p.1983-2003, 2005.

GARCIA, G. de O. Alterações químicas, físicas e mobilidade dos íons no soldecorrentes da aplicação de água residuária da lavagem e despolpa de frutos do cafeeiro conilon. Viçosa: UFV, 2003. 101p. (Dissertação de Mestrado)

HESPANHOL, I. Potencial de reuso de água no Brasil: agricultura, indústria, município e recarga de aquífero. In: MANCUSO, P. C. S; SANTOS, H. F. dos. Reúso de Água. $2^{\mathrm{a}}$ ed. Barueri: Manole, 2003.

PAGANINI, W. S. Reuso de água na agricultura. In: MANCUSO P. C. S.; SANTOS H. F. (Eds). Reuso de água. Baureri: Manole, p.339-401. 2003.

QUEIROZ, F. M.; MATOS, A. T.; PEREIRA, O. G.; OLIVEIRA, R. A. Características químicas de solo submetido ao tratamento com esterco líquido de suínos e cultivado com gramíneas forrageiras. Ciência Rural, v.34, n.05, p.1487-1492, 2004.

QUIN, B. F.; WOODS, P. H. Surface irrigation of pasture with treated sewage effluent. I. Nutrient status of soil and pastures. New Zealand Journal of Agricultural Research, v.21, p.419-426, 1978. 